\title{
In vitro approach to evaluate the fermentation pattern of inulin-rich food in obese individuals
}

\author{
Gaétan Kalala ${ }^{1,2}$, Bienvenu Kambashi ${ }^{1}$, Bernard Taminiau ${ }^{3}$, Martine Schroyen $^{2}$, Nadia Everaert ${ }^{2}$, \\ Yves Beckers ${ }^{2}$, Aurore Richel ${ }^{2}$, Patrick Njeumen ${ }^{2}$, Barbara Pachikian ${ }^{4}$, Audrey M. Neyrinck ${ }^{4}$, Sophie Hiel ${ }^{4}$, \\ Julie Rodriguez ${ }^{4}$, Papa A. Fall ${ }^{5}$, Georges Daube ${ }^{3}$, Jean-Paul Thissen ${ }^{6}$, Nathalie M. Delzenne ${ }^{4}$ and \\ Jérôme Bindelle ${ }^{2 *}$ \\ ${ }^{1}$ Department of Animal Production, Université de Kinshasa, Kinshasa-XI, DR Congo \\ ${ }^{2}$ TERRA Teaching and Research Centre, Gembloux Agro-Bio Tech, Liège University, B-5030 Liège, Belgium \\ ${ }^{3}$ Faculty of Veterinary Medicine, FARAH Centre, Liège University, B-400O Liège, Belgium \\ ${ }^{4}$ Metabolism and Nutrition Research Group, Université Catbolique de Louvain, UCLouvain, B-1200 Brussels, Belgium \\ ${ }^{5}$ Genalyse Partner SA, B-400O Liège, Belgium \\ ${ }^{6}$ Division of Endocrinology, Diabetes and Nutrition, Institut de Recherche Expérimentale et Clinique IREC, Université Catholique \\ de Louvain, Brussels, Belgium
}

(Submitted 4 April 2019 - Final revision received 5 October 2019 - Accepted 29 October 2019)

\section{Abstract}

Alterations of the gut microbiome have been associated with obesity and metabolic disorders. The gut microbiota can be influenced by the intake of dietary fibres with prebiotic properties, such as inulin-type fructans. The present study tested the hypothesis that obese individuals subjected for 12 weeks to an inulin-enriched $v$. inulin-poor diet have differential faecal fermentation patterns. The fermentation of cellulose and inulin hydrolysates of six different inulin-rich and inulin-poor vegetables of both groups was analysed in vitro on faecal inocula. The results showed that the microbiota from obese patients who received a fructan-rich diet for 3 weeks produces more gas and total SCFA compared with the microbiota taken from the same individuals before the treatment. Obese individuals fed with a low-fructan diet produce less gas and less SCFA compared with the treated group. The present study highlighted profound changes in microbiota fermentation capacity obtained by prebiotic intervention in obese individuals, which favours the production of specific bioactive metabolites.

Key words: In vitro fermentation: Obese adults: Fibre residues: Inulin

The large intestine of humans hosts an important microbial population that can reach $10^{10}-10^{11}$ bacteria cells/g of intestinal content, with nearly $400-1000$ species $^{(1-3)}$. This gut microbiota plays a key role in homeostasis and health status by interfering with digestion processes, preventing colonisation by pathogens and modulating the development of the immune system ${ }^{(4)}$. It also regulates a set of metabolic pathways of the host ${ }^{(5,6)}$. Many metabolic diseases, such as obesity, the metabolic syndrome, diabetes and gastrointestinal diseases such as cancer and inflammatory bowel disease, are related to alterations of gut microbiota composition and function, called dysbiosis ${ }^{(7,8)}$.

The gut microbiota is highly influenced by the diet. In particular, the undigested carbohydrates and proteins that reach the large intestine are subjected to fermentation. Hence, intestinal microbes produce gases, such as $\mathrm{H}_{2}$, carbon dioxide, methane, ammonia and hydrogen sulphide $\left(\mathrm{H}_{2} \mathrm{~S}\right)^{(9)}$, as well as various metabolites, such as SCFA and branched-chain fatty acids (BCFA), phenolic and indole compounds, biogenic amines and sulphur metabolites ${ }^{(10)}$.

All these compounds influence the physiological and metabolic functions in humans ${ }^{(11,12)}$. SCFA are linear carboxylic acids, including acetate, propionate and butyrate, and are produced from fermentation of carbohydrates and fibres. The main BCFA are iso-valerate, iso-butyrate and valerate ${ }^{(13)}$. BCFA originate from the fermentation of protein and the degradation of their constitutive amino acids ${ }^{(14)}$.

Several studies have demonstrated the impact of dietary fibres (DF) on gut microbial communities, using not only purified DF, such as resistant starch, $\beta$-glucan, fructooligosaccharides, sugar beet peptic oligosaccharides, guar

Abbreviations: BCFA, branched-chain fatty acid; DF, dietary fibre.

* Corresponding author: Professor Jérôme Bindelle, email jerome.bindelle@uliege.be 
gum, pea fibre and pectin, but also DF isolated from whole grains ${ }^{(11,15-18)}$. Among the DF, purified inulin and fructooligosaccharides were the first non-digestible carbohydrates evaluated for their prebiotic properties, since they can modulate the gut microbiota composition, with consequences on host physiology $^{(19)}$.

Fruits, cereals and vegetables are the major sources of DF in the human diet. Strong variation exists among food products regarding the amount and the type of DF they provide ${ }^{(20,21)}$. Soluble DF is potentially most effective in modulating intestinal microbiota. Carbohydrates embedded in a vegetable food matrix are likely to present a different functionality compared with purified fractions ${ }^{(22)}$.

Purified inulin and fructo-oligosaccharides, given as supplement, on obesity have been highlighted in both preclinical ${ }^{(23,24)}$ and clinical studies ${ }^{(25,26)}$. We have shown that only few vegetables provide significant amounts of inulin and fructooligosaccharides $^{(21)}$. It could be beneficial to encourage the consumption of inulin-rich vegetables and fruits, in the context of obesity, if their properties of interaction with the gut microbiota are maintained in a food matrix, and if they exert health effect in this particular context.

The present study addressed the question of the relevance of inulin-rich food in the modulation of the functionality of the gut microbiota, by performing an in vitro fermentation, using the faecal material obtained from two groups of obese individuals, before and after a dietary treatment differing by inulin intake. Obese patients received either a diet based on inulin-rich vegetables coupled with inulin supplementation or an inulin-poor diet coupled with maltodextrin supplementation as control for 3 months. The study assessed the ability of these treatments to modify the faecal microbiota composition and fermentation capacity in a humanised in vitro model of the gastrointestinal tract.

\section{Materials and methods}

The study was approved by the Faculty Hospital Ethics Committee of the Faculty of Medicine of the Catholic University of Louvain (Woluwe, Belgium) and was registered at clinicaltrial.gov as NCT03852069. The present study was conducted according to guidelines laid down in the declaration of Helsinki, and all procedures involving human patients were approved. Written informed consent was obtained from all patients.

The faeces of twelve obese patients (six females, six males) ranging in age from 21 to 62 years and with a BMI $>30 \mathrm{~kg} / \mathrm{m}^{2}$ were used. These patients were able to provide sufficient amounts of fresh faeces before (initial phase) and after a 3-month treatment, consisting of one of the two possible dietary instructions: a diet based on fructan-rich vegetables (treated group) and a diet based on vegetables poor in fructans (control group). Moreover, the treated group was supplemented with a daily dose (16 g) of inulin-type fructans (Fibrulin, Cosucra), and the control group was given $16 \mathrm{~g}$ of maltodextrin (Cargill).

Fructan intake (g/d) was evaluated by submitting the patients to a FFQ, and the calculation of fructans' intake was based on the analysis of fructan content in foodstuffs (vegetables, fruits and cereals) as reported ${ }^{(21,27-29)}$.

The true estimation of inulin and maltodextrin intake (compliance) was evaluated upon bring-back of empty and unused packets. To verify compliance related to the selected vegetable consumption, a phone call with all the patients was organised three times during the study (after 2 weeks, 1 and 2 months of treatment). A meeting with dietitians was also scheduled every month to ensure that patients followed the dietary advice and prepared their meal following the recipe book received at the start of the intervention. This recipe book describes several recipes based on vegetables enriched in fructans for the treated group and recipes with vegetables poor in fructans for the control group. The patients had to report weekly the number of meals corresponding to the selected recipes, or using the vegetables included in the recipes prepared in another way.

Fructans intake (g/d) was evaluated by submitting the patients to a FFQ created in order to include foodstuffs rich in fructans. Indeed, we have previously published the quantitative analysis of fructans in vegetables. The amount of fructans in cereals and fruits has been calculated taking into account published data.

The questionnaire has been validated by the dietitians implicated in the clinical follow-up. We propose to add the questionnaire (in French) as online Supplementary data. Using this questionnaire, fructan intake was calculated on the basis of fructans content analysis in foodstuffs (vegetables, fruits and cereals) as reported.

Faeces were used for in vitro fermentation of the indigestible fibre residue of vegetables rich (salsify and Jerusalem artichoke) and poor (asparagus, fennel, pumpkin and swede) in inulin, as well as purified fibres (inulin and cellulose), to compare the shifts in fermentation patterns resulting from the expected diet-induced changes in microbiota.

For this purpose, a two-step in vitro model of the pig gastrointestinal tract was adapted to human samples. It consists of the enzymatic hydrolysis of food material to simulate digestive processes occurring in the stomach and the small intestine, followed by an in vitro batch fermentation of the indigested residues using faeces as bacterial inoculum.

\section{Enzymatic hydrolysis}

Six vegetables were sampled in triplicates $(n 3)$ and steamed for 20-30 min: Jerusalem artichoke (Helianthus tuberous), salsify (Scorzonera bispanica), asparagus (Asparagus officinalis), pumpkin (Cucurbita maxima Duchesne ssp.), fennel (Foeniculum vulgare) and swede (Brassica napobrassica). These vegetables were chosen because they display a variable content of fructans, soluble DF and insoluble $\mathrm{DF}^{(21)}$.

Steamed vegetables were hydrolysed in vitro with porcine pepsin and pancreatin, to mimic digestion in the upper gut ${ }^{(30)}$, and undigested fibre residues were recovered using a $6 \mathrm{kDa}$ dialysis membrane placed in beakers containing distilled water that were under continuous agitation. After $24 \mathrm{~h}$, the undigested fibre residues remaining in the dialysis membrane were freeze-dried.

The composition of vegetables before and after enzymatic hydrolysis is listed in Table 1 . 
Table 1. Chemical composition of the ingredients and their hydrolysates used for fermentation $(n 3)(\mathrm{g} / 100 \mathrm{~g} \mathrm{DM})$ (Mean values with their standard errors)

\begin{tabular}{|c|c|c|c|c|c|c|c|c|c|c|c|c|c|c|c|c|c|c|c|}
\hline \multirow[b]{2}{*}{ Ingredients } & \multirow[b]{2}{*}{ Hydrolysis } & \multicolumn{2}{|c|}{ Starch } & \multicolumn{2}{|c|}{ OM } & \multicolumn{2}{|c|}{$\mathrm{CP}$} & \multicolumn{2}{|c|}{ IDF } & \multicolumn{2}{|c|}{ HMWSDF } & \multicolumn{2}{|c|}{ LMWSDF } & \multicolumn{2}{|c|}{ SDF } & \multicolumn{2}{|c|}{ TDF } & \multicolumn{2}{|c|}{ Fructans } \\
\hline & & Mean & SEM & Mean & SEM & Mean & SEM & Mean & SEM & Mean & SEM & Mean & SEM & Mean & SEM & Mean & SEM & Mean & SEM \\
\hline \multirow{2}{*}{ Asparagus } & & & 0.0 & & 0.9 & $15 \cdot 2$ & 0.1 & $25 \cdot 1$ & $3 \cdot 2$ & & 0.9 & 0.4 & 0.2 & $9 \cdot 3$ & $1 \cdot 0$ & $34 \cdot 4$ & $4 \cdot 2$ & 5 & 0.3 \\
\hline & $\mathrm{H}$ & 0.1 & 0.0 & 87.4 & 1.2 & $12 \cdot 4$ & 0.1 & 42.9 & $3 \cdot 1$ & 13.5 & 0.7 & 0.6 & 0.2 & $14 \cdot 1$ & 1.1 & $57 \cdot 0$ & 3.2 & 0.5 & \\
\hline \multirow[t]{2}{*}{ Fennel } & Cooked & $14 \cdot 1$ & 0.7 & 88.9 & 1.5 & 9.5 & 0.9 & $26 \cdot 9$ & 0.0 & $11 \cdot 2$ & 0.7 & 0.2 & 0.0 & 11.4 & 0.6 & $38 \cdot 3$ & 0.7 & 0.3 & 0 . \\
\hline & Hydrolysed & 0.1 & 0.0 & $82 \cdot 8$ & $2 \cdot 3$ & $7 \cdot 8$ & 0.6 & $53 \cdot 7$ & 0.3 & $16 \cdot 2$ & 0.3 & 0.5 & 0.2 & $16 \cdot 7$ & 0.1 & $70 \cdot 4$ & 4.9 & 0.3 & \\
\hline \multirow[t]{2}{*}{ Jerusalem artichoke } & Cooked & 0.1 & 0.0 & $93 \cdot 6$ & 1.8 & $11 \cdot 1$ & 0.1 & $6 \cdot 4$ & 0.6 & $17 \cdot 7$ & $4 \cdot 0$ & $40 \cdot 9$ & 2.5 & 2.0 & 5.5 & $78 \cdot 4$ & $6 \cdot 0$ & $68 \cdot 3$ & 0 . \\
\hline & Hydr & 0.1 & 0.0 & $89 \cdot 0$ & 1.8 & 9.5 & 0.1 & $12 \cdot 5$ & 0.6 & $28 \cdot 3$ & $2 \cdot 1$ & $42 \cdot 4$ & $3 \cdot 0$ & $70 \cdot 7$ & 5.5 & $83 \cdot 2$ & $6 \cdot 0$ & $68 \cdot 3$ & 0.7 \\
\hline \multirow[t]{2}{*}{ Pumpkin } & Cooked & $49 \cdot 3$ & 1,6 & $92 \cdot 8$ & 1.5 & $7 \cdot 4$ & 0.4 & $17 \cdot 2$ & $3 \cdot 1$ & $6 \cdot 8$ & 0.4 & $1 \cdot 1$ & 0.9 & 8.0 & 0.9 & 23.8 & 3.3 & $1 \cdot 1$ & \\
\hline & Hydrolysed & 30.5 & 0.4 & $86 \cdot 2$ & 1.7 & 6.5 & 0.6 & 37.8 & 1.8 & 11.0 & 0.5 & 0.9 & 0.3 & 11.9 & 0.2 & $49 \cdot 7$ & $2 \cdot 8$ & 1.3 & 0.5 \\
\hline \multirow[t]{2}{*}{ Salsify } & Cooked & 0.2 & 0.1 & $96 \cdot 8$ & 0.8 & $11 \cdot 1$ & 0.0 & $8 \cdot 4$ & 0.2 & $11 \cdot 0$ & $2 \cdot 6$ & $61 \cdot 6$ & $7 \cdot 8$ & $72 \cdot 6$ & 8.5 & $81 \cdot 0$ & $8 \cdot 7$ & 71.9 & $5 \cdot 7$ \\
\hline & Hydrolysed & 0.2 & 0.1 & $89 \cdot 7$ & 0.8 & 8.5 & 0.1 & $15 \cdot 6$ & 0.2 & $22 \cdot 1$ & 1.3 & $44 \cdot 3$ & $7 \cdot 8$ & $66 \cdot 4$ & 8.5 & $82 \cdot 0$ & $8 \cdot 7$ & 71.9 & \\
\hline \multirow[t]{2}{*}{ Swede } & & $16 \cdot 8$ & 0.2 & $93 \cdot 6$ & $2 \cdot 5$ & $8 \cdot 3$ & $2 \cdot 0$ & 23.5 & 0.5 & & $2 \cdot 2$ & 1.0 & 0.0 & $17 \cdot 7$ & 1.5 & $36 \cdot 3$ & 0.8 & 0.6 & 0.3 \\
\hline & Hydrolysed & 0.4 & 0.1 & $81 \cdot 8$ & 1.2 & $6 \cdot 7$ & 0.4 & $48 \cdot 8$ & 0.5 & 24.6 & 0.5 & 0.4 & 0.0 & $25 \cdot 0$ & 1.6 & $73 \cdot 8$ & 1.4 & 0.9 & 0.1 \\
\hline
\end{tabular}

OM, organic matter; CP, crude protein; IDF, insoluble dietary fibre; HMWSDF, high molecular weight soluble dietary fibre; LMWSDF, low molecular weight soluble dietary fibre; SDF, soluble dietary fibre; TDF, total dietary fibre.

\section{In vitro fermentation using human faecal inoculums}

Faecal material of the patients was collected in a plastic container with lid for a hermetic closure (Commode specimen collection system 02-544-208, Fisher Scientific), placed under anaerobiosis by inserting an Anaerocult $\mathrm{C}$ bag (Merck KG\&A) and kept in a cooler $\left(4^{\circ} \mathrm{C}\right)$ during transportation to the laboratory for further processing. Immediately upon arrival, faecal samples were conditioned as follows in a glove box (In vivo2 1000, Dual Chambers, Hypoxia Workstation, Ruskinn Technologies) fed with a stream of $\mathrm{N}_{2}$ and gas mixture $\left(8 \% \mathrm{H}_{2}, 8 \% \mathrm{CO}_{2}, 84 \% \mathrm{~N}_{2}\right): 25 \mathrm{~g}$ of faecal material was introduced into sterile stomacher bags $(384 \mathrm{ml}$, Nasco Whirl-Park) using sterile spoons (Spoons B01041, Nasco).

The bags were immediately quenched in liquid $\mathrm{N}_{2}$ to ensure ultra-fast freezing, preventing the destruction of the microorganisms, and conditioned samples were kept in a freezer at $-80^{\circ} \mathrm{C}^{(31)}$ until further use. Faeces samples were processed within a maximum of $2 \mathrm{~h}$ following their emission.

The fermentation was carried out according to the protocol of Bindelle et al. ${ }^{(30)}$ as modified by Tran et al. ${ }^{(32)}$. For a given individual, both faecal inocula, that is, faeces collected before and after the dietary treatment, were processed on the same day. The day before fermentation, $0 \cdot 1 \mathrm{~g}$ of substrate sample (residues of the hydrolysis of six steamed vegetables, and purified inulin and cellulose) was weighed in triplicate into $50 \mathrm{ml}$ sterile glass vials. Three blanks served as a control. One litre of Menke and Steingass' buffer ( $\mathrm{pH}$ 6.8) mixture devoid of $\mathrm{Na}_{2} \mathrm{~S}^{(33)}$ was prepared and bubbled with $\mathrm{N}_{2}$. Mucus carriers were impregnated with mucin agar. The next day, all procedures were performed in the glove box at $37^{\circ} \mathrm{C}$. The $25 \mathrm{~g}$ bag of faecal sample was thawed by immersion in Menke and Steingass' buffer, to yield a concentration of 1:40 (w/v) and homogenised using a stomacher (Awel microbiology, Mixwel+) for $1 \mathrm{~min}$. Three mucus carriers were placed in each glass vials, and $15 \mathrm{ml}$ of inoculum (faeces and buffer) was poured into the vials containing the substrates. These were air-tight closed and incubated in a water bath at $37^{\circ} \mathrm{C}$ for $24 \mathrm{~h}$. The pressure in the headspace of the bottles was read at 2, 5, 8, 12, 16, 20 and $24 \mathrm{~h}$, using a Digital Pressure Gauge (Tracker 200) $^{(34)}$ and converted into volume applying the law of Boyle and Marriott.
After fermentation for $24 \mathrm{~h}$, the supernatants were emptied into $15 \mathrm{ml}$ centrifuge conical tubes and stored at $-20^{\circ} \mathrm{C}$ for analyses of the SCFA. The gas production curve was modelled according to the monophasic model of Groot et al. ${ }^{(35)}$, which allows describing fermentation kinetics using four parameters: the total volume of gas produced at $24 \mathrm{~h}$ (A: $\mathrm{ml} / \mathrm{g} \mathrm{DM})$; the time at which half of the total gas volume is obtained (B: h); the maximum rate of gas production (Rmax: $\mathrm{ml} / \mathrm{h}$ per $\mathrm{g} \mathrm{DM}$ ) and the time at which the maximum rate of production is reached (Tmax: h).

\section{Analysis of SCFA}

Fermentation supernatants and inoculum of the twelve donors used in the fermentation study were analysed for SCFA and BCFA contents, by using a Waters 2690 HPLC system (Waters) fitted with an Aminex HPX-87 H column $(300 \mathrm{~mm} \times 78 \mathrm{~mm}$; Bio-Rad Laboratories) combined with a Waters 486 tuneable absorbance detector set at $210 \mathrm{~nm}$.

In vitro fermentation data were corrected for the content of the blanks, as well as the inocula. The sterile bottle containing $15 \mathrm{ml}$ of fermentation supernatants was vortexed for $1 \mathrm{~min}$, and $2 \mathrm{ml}$ aliquot was centrifuged at $13000 \mathrm{rpm}$ for $15 \mathrm{~min}$. Aliquot $(1.5 \mathrm{ml})$ of the supernatants was transferred to a vial, and $\mathrm{pH}$ was adjusted to between one and three, using $0 \cdot 1 \mathrm{M} \mathrm{HCl}$.

\section{Statistical analysis}

The analysis of the kinetic of fermentation and the SCFA of the fermented ingredients with the faeces of two groups of obese patients was made by comparing the two groups according to the period before and after intervention by ANOVA, using the MIXED procedure of SAS 9.4 software (SAS Inc.). Patients ( $n 6$ ) were considered as the experimental unit, and the period was the effect that was tested.

\section{Results}

The compliance of powdered native inulin and maltodextrin packets intake reached 98.4 and $95.5 \%$ for treated and control 
G. Kalala et al.

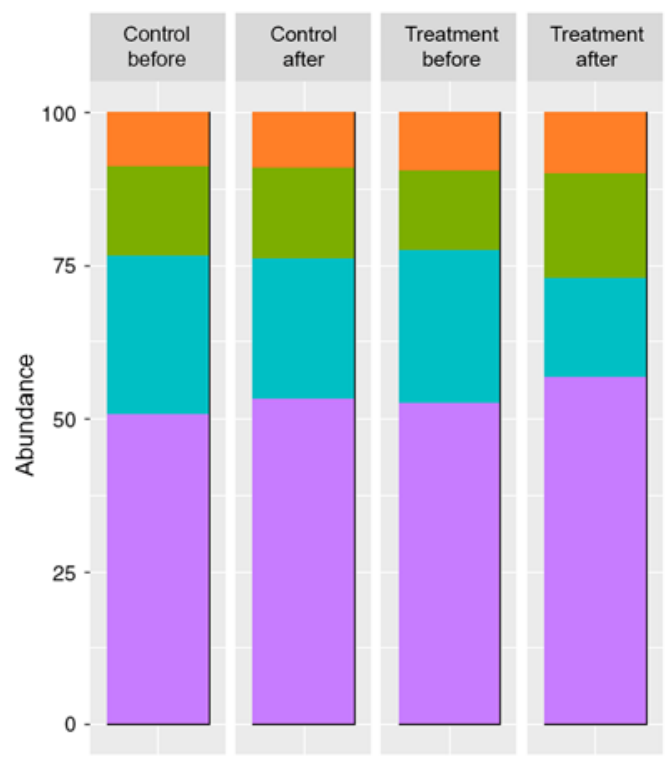

Fig. 1. SCFA contents in the faeces of two groups of donors before and after the dietary treatment (molar ratio \%) ( $n 6)$. Branched-chain fatty acids (BCFA) include iso-butyrate, valerate and iso-valerate. $\square, \mathrm{BCFA} \%$; $\square$, butyrate $\%$; $\square$, propionate $\% ;$, , acetate $\%$.

groups, respectively. Regarding the qualitative consumption of vegetables enriched in fructans (for the treated group) or vegetables poor in fructans (for the control group), data are available for five patients on six in each group. Based on the weekly follow-up of cooked recipes, patients consumed at least a mean of 5.6 and 4.4 of different recommended vegetables per week in the treated and control groups, respectively, based on the FFQ.

After 3 months of intervention, dietary fructan intake increased significantly in the treated group, whereas no significant effect occurred in the control group (before: 2.54 and $2.22 \mathrm{~g} / \mathrm{d} v$. after: 11.03 and $3.6 \mathrm{~g} / \mathrm{d}$ for the treated group and control groups, respectively).

The results displayed in Table 1 demonstrate that the enzymatic hydrolysis allowed the collection of a significant amount of fibrous residues. These results show that the hydrolysis has led to a considerable decrease of the starch.

The faeces collected from patients used as inocula, displayed different SCFA and BCFA contents and production profiles according to the period (before $v$. after a 3 -month treatment) and the treatment undergone by the patient (treated group $v$. control group) (Fig. 1).

Both treatments provoked an increase in SCFA contents of faeces, with a significant difference for the treated group when comparing before and after treatment, but no significant difference before and after for the control group (before: 5.89 and $5.27 \mathrm{mg} / \mathrm{g} v$. after: 10.12 and $8.19 \mathrm{mg} / \mathrm{g}$ for treated and control groups, respectively).

The molar ratios of butyrate (treated group) and acetate (treated and control groups) showed a significant difference between the two phases (butyrate before: $13 \cdot 1$ and $14.8 \% v$. after: 17.1 and $14.9 \%$, for treated and control groups, respectively; acetate before: 52.5 and $50.6 \% v$. after: 56.7 and $53.1 \%$ for treated and control groups, respectively).
An increase in microbial fermentation activity (gas production) after treatment was also observed for the treated group, since patients after a 3-month treatment displayed a faster and more extended fermentation, as indicated by an increased Rmax and by higher final gas volumes (A) for most ingredients. The control group did not change gas production after treatment (Table 2).

The fermentation kinetics of fibres and vegetable extracts analysed in vitro also showed interesting results. The SCFA production upon $24 \mathrm{~h}$ was higher for the treated group after dietary intervention with significant differences compared with the phase before, while the control group did not significantly modify the fermentation profile of any of the two types of ingredients (vegetables and purified fibres) (Table 3).

Indeed, we observe an increase of total SCFA in the treated group after the dietary intervention when compared with the initial phase, for both vegetables (225-298 v. 465-521 mg/g DM before and after treatment, respectively) and purified carbohydrate (137-315 v. 218-512 mg/g DM before and after treatment, respectively). In addition, the main organic acids, namely, acetate, propionate and butyrate, showed significant differences before and after intervention.

An increase in butyrate was observed after the intervention in the treated group for salsify, Jerusalem artichoke, asparagus and fennel (5-12\% v. 7-14\% before and after the treatment, respectively). Conversely, the control group showed a decrease in SCFA, with slight tendencies to increased butyrate in the postphase (4-16\% v. $7-16 \%$ before and after the treatment, respectively).

The principal component analysis for parameters related to fermentation kinetics and the SCFA production showed that in the post-treatment phase, the total SCFA, A, Rmax, butyrate and acetate were aligned on the same axis as the treated group. Conversely, Tmax, B, propionate and BCFA were aligned with the control group and inversely proportional to the treated group, with a negative correlation (Fig. 2).

Finally, in addition to inulin, which displayed high fermentation, salsify and Jerusalem artichoke were the vegetables that approximated inulin the most in terms of fast fermentation patterns. Cellulose exhibited the slowest fermentation. Regarding the total volume of gas produced, salsify came first, followed by inulin, Jerusalem artichoke and swede. Again, cellulose was the least fermentable.

\section{Discussion}

In recent decades, the importance of gut microbiota on health has raised the attention of many, especially concerning the relationship between gut microbiota and obesity ${ }^{(36)}$. Some studies have shown that the fructan content of vegetables positively impacts on the kinetic of fermentation associated with the gut microbial alteration ${ }^{(37-39)}$. DF is a major factor driving the composition and metabolic activity of colonic microbiota ${ }^{(19,40)}$. Data from epidemiological studies have shown that diets high in fibre are associated with reduced risk of metabolic diseases, such as diabetes and obesity, and SCFA are often presented as key metabolites involved in the improvement of host 
Table 2. Effects of the ingredient and the period (before and after dietary treatment) on fermentation kinetics modelled according to Groot et al. ${ }^{(35)}$

(Mean values with their standard errors)

\begin{tabular}{|c|c|c|c|c|c|c|c|c|c|c|}
\hline \multirow[b]{2}{*}{ Ingredients } & \multirow[b]{2}{*}{ Patients } & \multirow[b]{2}{*}{ Period } & \multicolumn{2}{|c|}{ A } & \multicolumn{2}{|c|}{ B } & \multicolumn{2}{|c|}{ Rmax } & \multicolumn{2}{|c|}{ Tmax } \\
\hline & & & Mean & SEM & Mean & SEM & Mean & SEM & Mean & SEM \\
\hline \multicolumn{11}{|l|}{ Vegetables } \\
\hline \multirow[t]{4}{*}{ Asparagus } & Treated & Before & $124^{b}$ & 27 & 8.7 & 1.5 & $10.5^{b}$ & 2.9 & 5.9 & 1.4 \\
\hline & & After & $207^{a}$ & 11 & $8 \cdot 2$ & 1.4 & $15 \cdot 7^{\mathrm{a}}$ & 1.0 & 5.4 & $1 \cdot 1$ \\
\hline & Control & Before & $155^{\mathrm{b}}$ & 35 & $8 \cdot 2$ & 1.4 & $13 \cdot 9^{a, b}$ & 3.3 & $5 \cdot 7$ & 1.3 \\
\hline & & After & $135^{\mathrm{b}}$ & 13 & 9.5 & 1.6 & $10 \cdot 8^{b}$ & 1.5 & $6 \cdot 7$ & 1.9 \\
\hline \multirow[t]{4}{*}{ Fennel } & Treated & Before & $141^{\mathrm{c}}$ & 30 & 8.6 & 1.3 & $12 \cdot 4^{\mathrm{b}}$ & 3.5 & 5.9 & 1.3 \\
\hline & & After & $230^{a}$ & 12 & $8 \cdot 1$ & 1.5 & $17 \cdot 0^{a}$ & 0.9 & $5 \cdot 8$ & 1.2 \\
\hline & Control & Before & $182^{b}$ & 52 & $8 \cdot 1$ & 1.7 & $17 \cdot 2^{\mathrm{a}}$ & 5.4 & $5 \cdot 8$ & 1.4 \\
\hline & & After & $146^{b, c}$ & 19 & 9.2 & 1.6 & $12 \cdot 4^{\mathrm{b}}$ & $2 \cdot 1$ & $6 \cdot 8$ & 1.7 \\
\hline \multirow[t]{4}{*}{ Jerusalem artichoke } & Treated & Before & $202^{b}$ & 44 & 8.2 & 1.6 & $21 \cdot 9^{a, b}$ & $5 \cdot 0$ & $6 \cdot 6$ & 1.8 \\
\hline & & After & $281^{a}$ & 10 & 7.4 & $2 \cdot 1$ & $21 \cdot 3^{b}$ & 1.0 & 5.4 & 1.7 \\
\hline & Control & Before & $217^{b}$ & 45 & 7.4 & $2 \cdot 1$ & $26 \cdot 5^{\mathrm{a}}$ & $7 \cdot 3$ & $5 \cdot 8$ & $2 \cdot 1$ \\
\hline & & After & $197^{b}$ & 11 & $8 \cdot 2$ & $2 \cdot 1$ & $21 \cdot 6^{\mathrm{b}}$ & 4.4 & $6 \cdot 6$ & $2 \cdot 2$ \\
\hline \multirow[t]{4}{*}{ Pumpkin } & Treated & Before & $158^{b}$ & 34 & 8.4 & 1.5 & $14 \cdot 7^{\mathrm{b}}$ & 3.5 & $6 \cdot 2$ & 1.6 \\
\hline & & After & $242^{a}$ & 11 & $7 \cdot 7$ & $2 \cdot 1$ & $17 \cdot 7^{\mathrm{a}, \mathrm{b}}$ & 0.9 & $5 \cdot 3$ & 1.7 \\
\hline & Control & Before & $185^{\mathrm{b}}$ & 53 & $7 \cdot 7$ & $2 \cdot 1$ & $20 \cdot 4^{a}$ & $7 \cdot 4$ & 5.7 & 1.9 \\
\hline & & After & $152^{\mathrm{b}}$ & 32 & 8.0 & 2.0 & $14 \cdot 9^{\mathrm{b}}$ & $6 \cdot 7$ & $6 \cdot 4$ & 1.8 \\
\hline \multirow[t]{4}{*}{ Salsify } & Treated & Before & $210^{\mathrm{b}}$ & 55 & 7.9 & 1.4 & $23 \cdot 2^{a, b}$ & $6 \cdot 7$ & $6 \cdot 3$ & 1.6 \\
\hline & & After & $332^{a}$ & 18 & $7 \cdot 3$ & 1.8 & $25 \cdot 3^{a, b}$ & 1.3 & $5 \cdot 6$ & 1.5 \\
\hline & Control & Before & $222^{b}$ & 55 & $7 \cdot 3$ & 1.8 & $27 \cdot 4^{\mathrm{a}}$ & 7.9 & $5 \cdot 7$ & 1.9 \\
\hline & & After & $198^{\mathrm{b}}$ & 10 & 8.1 & $2 \cdot 2$ & $21.9^{b}$ & 4.7 & 6.5 & $2 \cdot 2$ \\
\hline \multirow[t]{4}{*}{ Swede } & Treated & Before & $144^{\mathrm{C}}$ & 34 & 8.5 & 1.3 & $12 \cdot 9^{b}$ & 3.9 & $6 \cdot 1$ & 1.3 \\
\hline & & After & $243^{a}$ & 17 & $8 \cdot 3$ & 1.5 & $18 \cdot 1^{a}$ & 1.4 & $5 \cdot 8$ & 1.2 \\
\hline & Control & Before & $184^{b}$ & 50 & $8 \cdot 3$ & 1.5 & $17 \cdot 2^{\mathrm{a}, \mathrm{b}}$ & $5 \cdot 0$ & $5 \cdot 9$ & 1.4 \\
\hline & & After & $159^{b, c}$ & 20 & 9.5 & 1.8 & $13 \cdot 5^{a, b}$ & $2 \cdot 8$ & $7 \cdot 1$ & $2 \cdot 0$ \\
\hline \multicolumn{11}{|c|}{ Purified carbohydrate oligosaccharides } \\
\hline \multirow{4}{*}{ Cellulose } & Treated & Before & $77^{\mathrm{b}}$ & 20 & $6 \cdot 8$ & 1.3 & 7.9 & $2 \cdot 8$ & $4 \cdot 2$ & 1.5 \\
\hline & & After & $143^{a}$ & 14 & 5.9 & $1 \cdot 3$ & $12 \cdot 0$ & 1.0 & 3.6 & 1.2 \\
\hline & Control & Before & $92^{b}$ & 16 & $5 \cdot 9$ & 1.3 & $10 \cdot 4$ & $2 \cdot 2$ & 3.3 & 1.0 \\
\hline & & After & $75^{b}$ & 4 & 6.6 & 1.6 & 8.0 & 1.9 & 3.9 & 1.5 \\
\hline \multirow[t]{4}{*}{ Inulin } & Treated & Before & $241^{\mathrm{b}}$ & 62 & 8.5 & 1.5 & $24 \cdot 1^{a, b}$ & $6 \cdot 3$ & 6.6 & 1.8 \\
\hline & & After & $317^{a}$ & 18 & 7.4 & 1.4 & $26 \cdot 1^{a, b}$ & 1.0 & 5.3 & $1 \cdot 1$ \\
\hline & Control & Before & $238^{\mathrm{b}}$ & 53 & 7.4 & 1.4 & $27 \cdot 4^{\mathrm{a}}$ & 7.0 & $5 \cdot 8$ & 1.5 \\
\hline & & After & $213^{b}$ & 17 & 8.5 & $2 \cdot 0$ & $22 \cdot 7^{\mathrm{b}}$ & 4.4 & $6 \cdot 9$ & 1.9 \\
\hline
\end{tabular}

A, total volume of gas produced $(\mathrm{ml} / \mathrm{g} \mathrm{DM}) ; \mathrm{B}$, time at which half of the total gas volume is obtained $(\mathrm{h}) ; \mathrm{Rmax}$, maximum rate of gas production $(\mathrm{ml} / \mathrm{h} \times \mathrm{g} \mathrm{DM})$; Tmax, time at which the maximum rate of production is reached $(\mathrm{h})$.

a,b,c For one ingredient, values followed by unlike letters in a column indicate that means differed at a significance level of 0.05 .

physiology ${ }^{(41,42)}$. However, the studies relating the impact of inulin on SCFA in obese humans have been obtained through the analysis in the faecal samples, that lead to controversial data, and do not always reflect SCFA production ${ }^{(25)}$. The faecal microbiota following a 3-month treatment with fructans has a direct impact on the fermentative capacity of the faeces since a faster fermentation (assessed by gas production) was observed combined with an increased butyrate and acetate production in the treated group. The higher butyrate production at the posttreatment period corroborated the results obtained by Koecher et al. ${ }^{(11)}$, who also analysed the inoculum of non-obese people subjected to a diet rich in purified inulin-type fructans. The post-intervention data obtained in the present trial also showed an increase in total SCFA produced from the inoculum of obese patients that were given the low-inulin diet.

The effect on total SCFA mirrored those obtained by other authors, who specified that total production of SCFA is correlated with the total volume of gas produced. Several criteria, such as the type and amount of substrate ingested, colon integrity and genetics of individual, can influence the production of SCFA $^{(43-45)}$.
The content of fructan in the food products appeared to be the major factor driving the production of SCFA, in the present investigation. Given these results and those obtained by some researchers in similar studies ${ }^{(45,46)}$, it can be confirmed that vegetables with a high-fructan content increase the production of SCFA in a human in vitro model, but to a lesser extent than the purified inulin, although considerably more than the vegetables poor in inulin. Even though insoluble DF are less fermentable ${ }^{(47)}$, their importance in the approach of obesity is not negligible. Vegetables rich in insoluble fibres in the present study showed greater parameters of fermentation kinetics and higher SCFA production than those obtained for cellulose in an in vitro model. SCFA are recognised fermentation products of great importance for health, and which perform several functions, such as the regulation of absorption of water and minerals, the reduction of the $\mathrm{pH}$ of the colon thus inhibiting the development of pathogens present, while promoting the growth of beneficial bacteria ${ }^{(48)}$. Thus, it should be understood that, the relationships between fermentable carbohydrates and metabolic yield depend on the composition of the microbial community and the metabolic characteristics of each anaerobic bacterium ${ }^{(49)}$. 
Table 3. Impact of the ingredient and the period (before and after treatment) on total production of SCFA (mg/g DM) and molar ratio (\%) (Mean values with their standard errors)

\begin{tabular}{|c|c|c|c|c|c|c|c|c|c|c|c|c|}
\hline \multirow[b]{2}{*}{ Ingredients } & \multirow[b]{2}{*}{ Patients } & \multirow[b]{2}{*}{ Period } & \multicolumn{2}{|c|}{ Total SCFA } & \multicolumn{2}{|c|}{ Acetate } & \multicolumn{2}{|c|}{ Propionate } & \multicolumn{2}{|c|}{ Butyrate } & \multicolumn{2}{|c|}{ BCFA } \\
\hline & & & Mean & SEM & Mean & SEM & Mean & SEM & Mean & SEM & Mean & SEM \\
\hline \multicolumn{13}{|l|}{ Vegetables } \\
\hline \multirow[t]{4}{*}{ Asparagus } & \multirow[t]{2}{*}{ Treated } & Before & $225^{b}$ & 62 & $52^{b}$ & 0.0 & $34^{a, b}$ & 0.0 & 5 & 0.0 & $9^{a}$ & 0.0 \\
\hline & & After & $462^{a}$ & 97 & $56^{a}$ & 0.0 & $32^{b}$ & 0.0 & 7 & 0.1 & $5^{b}$ & 0.0 \\
\hline & \multirow[t]{2}{*}{ Control } & Before & $242^{\mathrm{b}}$ & 49 & $53^{a, b}$ & 0.2 & $37^{a}$ & 0.1 & 7 & 0.0 & $3^{b}$ & 0.0 \\
\hline & & After & $235^{b}$ & 31 & $50^{\mathrm{b}}$ & 0.1 & $36^{a}$ & 0.0 & 8 & 0.0 & $6^{a, b}$ & 0.0 \\
\hline \multirow[t]{4}{*}{ Fennel } & \multirow[t]{2}{*}{ Treated } & Before & $245^{b}$ & 53 & $67^{a}$ & 0.1 & $22^{a}$ & 0.0 & $5^{b}$ & 0.0 & $6^{a, b}$ & 0.0 \\
\hline & & After & $405^{a}$ & 65 & $68^{a}$ & 0.1 & $22^{a}$ & 0.0 & $7^{\mathrm{a}, \mathrm{b}}$ & 0.1 & $4^{b}$ & 0.0 \\
\hline & \multirow[t]{2}{*}{ Control } & Before & $280^{a, b}$ & 43 & $63^{b}$ & 0.1 & $25^{a}$ & 0.1 & $8^{a, b}$ & 0.0 & $4^{b}$ & 0.0 \\
\hline & & After & $252^{b}$ & 45 & $65^{a, b}$ & 0.1 & $17^{\mathrm{b}}$ & 0.1 & $10^{\mathrm{a}}$ & 0.0 & $8^{a}$ & 0.0 \\
\hline \multirow[t]{4}{*}{ Jerusalem artichoke } & \multirow[t]{2}{*}{ Treated } & Before & $280^{\mathrm{b}}$ & 92 & $57^{\mathrm{b}}$ & 0.0 & $27^{a}$ & 0.1 & $10^{b}$ & 0.1 & $6^{a}$ & 0.0 \\
\hline & & After & $479^{a}$ & 85 & $61^{b}$ & 0.0 & $23^{b}$ & 0.1 & $14^{a}$ & 0.1 & $2^{b}$ & 0.0 \\
\hline & \multirow[t]{2}{*}{ Control } & Before & $293^{b}$ & 45 & $62^{b}$ & 0.0 & $27^{a}$ & 0.0 & $10^{\mathrm{b}}$ & 0.0 & $1^{b}$ & 0.0 \\
\hline & & After & $284^{b}$ & 37 & $67^{a}$ & 0.1 & $19^{c}$ & 0.0 & $12^{a, b}$ & 0.0 & $2^{b}$ & 0.0 \\
\hline \multirow[t]{4}{*}{ Pumpkin } & \multirow[t]{2}{*}{ Treated } & Before & $254^{b}$ & 74 & $58^{b}$ & 0.0 & $28^{b}$ & 0.1 & $10^{\mathrm{b}}$ & 0.0 & 4 & 0.0 \\
\hline & & After & $437^{a}$ & 22 & $63^{a}$ & 0.0 & $20^{c}$ & 0.1 & $14^{a}$ & 0.0 & 3 & 0.0 \\
\hline & \multirow[t]{2}{*}{ Control } & Before & $269^{b}$ & 45 & $51^{c}$ & 0.1 & $34^{a}$ & 0.1 & $10^{b}$ & 0.0 & 5 & 0.0 \\
\hline & & After & $247^{b}$ & 57 & $50^{c}$ & 0.1 & $34^{a}$ & 0.1 & $11^{a, b}$ & 0.1 & 5 & 0.0 \\
\hline \multirow[t]{4}{*}{ Salsify } & \multirow[t]{2}{*}{ Treated } & Before & $298^{b}$ & 85 & $72^{\mathrm{a}}$ & 0.0 & $14^{c}$ & 0.0 & 12 & 0.1 & 2 & 0.0 \\
\hline & & After & $521^{a}$ & 76 & $64^{b, c}$ & 0.0 & $20^{b}$ & 0.1 & 13 & 0.1 & 3 & 0.0 \\
\hline & \multirow[t]{2}{*}{ Control } & Before & $322^{b}$ & 48 & $62^{c}$ & 0.1 & $26^{a}$ & 0.0 & 10 & 0.0 & 2 & 0.0 \\
\hline & & After & $317^{\mathrm{b}}$ & 36 & $66^{b}$ & 0.1 & $17^{\mathrm{b}, \mathrm{c}}$ & 0.0 & 13 & 0.0 & 4 & 0.0 \\
\hline \multirow[t]{4}{*}{ Swede } & Treated & Before & $264^{b}$ & 53 & $60^{c}$ & 0.0 & $29^{a}$ & 0.1 & 6 & 0.0 & 5 & 0.0 \\
\hline & & After & $449^{a}$ & 88 & $71^{a}$ & 0.0 & $20^{b}$ & 0.1 & 7 & 0.0 & 2 & 0.0 \\
\hline & Control & Before & $291^{b}$ & 43 & $61^{c}$ & 0.0 & $29^{a}$ & 0.0 & 8 & 0.0 & 2 & 0.0 \\
\hline & & After & $253^{b}$ & 46 & $67^{b}$ & 0.1 & $22^{b}$ & 0.1 & 8 & 0.0 & 3 & 0.0 \\
\hline Purified carbohydrate o & saccharide & & & & & & & & & & & \\
\hline Cellulose & Treated & Before & 137 & 18 & $43^{b}$ & 0.0 & $19^{c}$ & 0.0 & $10^{\mathrm{b}}$ & 0.0 & $27^{a}$ & 0.0 \\
\hline & & After & 218 & 20 & $38^{c}$ & 0.0 & $12^{d}$ & 0.0 & $22^{\mathrm{a}}$ & 0.0 & $28^{a}$ & 0.0 \\
\hline & Control & Before & 146 & 17 & $50^{\mathrm{a}}$ & 0.1 & $27^{b}$ & 0.1 & $4^{c}$ & 0.1 & $19^{b}$ & 0.0 \\
\hline & & After & 131 & 17 & $33^{d}$ & 0.1 & $44^{a}$ & 0.1 & $7^{\mathrm{b}, \mathrm{c}}$ & 0.0 & $16^{b}$ & 0.0 \\
\hline Inulin & Treated & Before & $315^{\mathrm{b}}$ & 84 & $58^{a, b}$ & 0.0 & $20^{b}$ & 0.1 & $21^{a}$ & 0.0 & $1^{c}$ & 0.0 \\
\hline & & After & $512^{a}$ & 67 & $49^{c}$ & 0.0 & $25^{a}$ & 0.0 & $21^{a}$ & 0.0 & $5^{b}$ & 0.0 \\
\hline & Control & Before & $306^{b}$ & 91 & $55^{b}$ & 0.1 & $27^{a}$ & 0.0 & $16^{b}$ & 0.0 & $2^{b, c}$ & 0.0 \\
\hline & & After & $284^{b}$ & 79 & $59^{a}$ & 0.1 & $16^{c}$ & 0.0 & $16^{\mathrm{b}}$ & 0.0 & $9^{a}$ & 0.0 \\
\hline
\end{tabular}

BCFA, branched-chain fatty acids regrouping iso-butyrate, valerate and iso-valerate.

$a, b, c, d$ For one ingredient, values followed by unlike letters in a column indicate that the organic acids before and after treatments differ at a significance level of 0.05 .

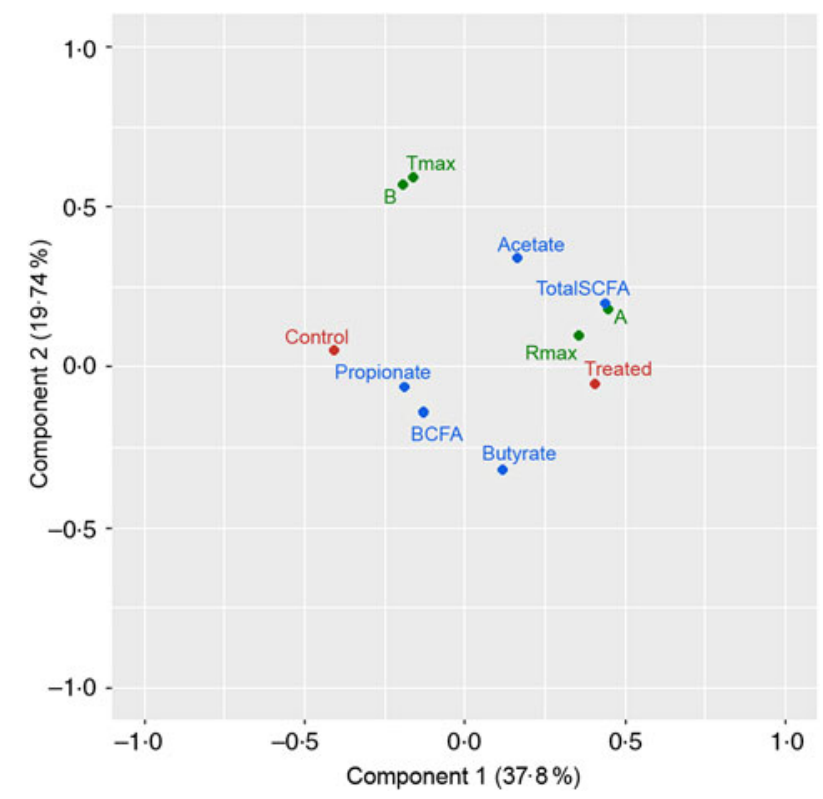

Fig. 2. Principal component analysis for kinetic parameters and SCFA of fermented ingredients after the treatment $(n 6)$. BCFA, branched-chain fatty acids.
Given the results of the present study and in comparison with other investigations that analysed the SCFA and gut microbiota profile $^{(49)}$, we expect that the large production in the present study will correlate with the modification of the microbiota of the intestinal tract of patients in the treated group. This was observed by the very high rate of fermentation and the significant production of butyrate. Apart from the ability to produce a significant amount of SCFA during fermentation, another benefit of a high-fibre diet is to stimulate the growth of the gut bacteria essential for health.

\section{Conclusion}

Inulin-type fructans are involved in the modulation of the gut microbiota and alter the production of both gas and SCFA, during fermentation. An inulin-type fructan intervention in one group of obese patients produced a higher gas volume and higher SCFA amount in vitro, with a trend towards increasing amounts of butyrate. In contrast, the control group presented a lower gas volume and lower total SCFA, after the study trial compared with the initial (pre-trial) phase. We thus confirm that in obese individuals, the faecal microbiota exhibits a higher capacity to 
modulate SCFA production when they were pretreated with a diet rich and supplemented with inulin. The relevance of such effects on the metabolic response towards inulin-rich diet in a large cohort of obese patients is currently under investigation.

\section{Acknowledgements}

The authors thank the dietitians Coralie Franay, Marie Barea and Marjorie Fadeur.

This work was co-funded by the Walloon Government (Namur, Belgium) and Liège University in the framework of the FOOD4GUT excellence research project. G. K. was funded by a PhD grant of Wallonie-Bruxelles International (WBI, Brussels).

B. P., A. N., S. H., J. P. T., N. D. and J. B. designed the research; G. K., B. K., N. E., Y. B., A. R., P. N., B. P., S. H. and J. R. conducted the research; G. K., B. K., B. T., M. S., P. N. and P. F. analysed the data and performed statistical analysis; G. K. and J. B. wrote the paper; J. B. had primary responsibility for final content. All authors read and approved the final manuscript.

None of the authors has any conflicts of interest to declare.

\section{Supplementary material}

For supplementary material referred to in this article, please visit https://doi.org/10.1017/S0007114519002915

\section{References}

1. Quigley EMM (2013) Gut bacteria in health and disease. Gastroenterol Hepatol (N Y) 9, 560-569.

2. Gill SR, Pop M, DeBoy RT, et al. (2006) Metagenomic analysis of the human distal gut microbiome. Science $\mathbf{3 1 2}$, 1355-1359.

3. Egert M, de Graaf AA, Smidt H, et al. (2006) Beyond diversity: functional microbiomics of the human colon. Trends Microbiol 14, 86-91.

4. Maukonen J \& Saarela M (2015) Human gut microbiota: does diet matter? Proc Nutr Soc 74, 23-36.

5. Erejuwa OO, Sulaiman SA \& Ab Wahab MS (2014) Modulation of gut microbiota in the management of metabolic disorders: the prospects and challenges. Int J Mol Sci 15, 4158-4188.

6. Sekirov I, Russell SL, Antunes LC, et al. (2010) Gut microbiota in health and disease. Physiol Rev 90, 859-904.

7. Ley RE, Turnbaugh PJ, Klein S, et al. (2006) Human gut microbes associated with obesity. Nature 444, 1038.

8. Peterson DA, Frank DN, Pace NR, et al. (2008) Metagenomic approaches for defining the pathogenesis of inflammatory bowel diseases. Cell Host Microbe 3, 417-427.

9. Poelaert C, Despret X, Sindic M, et al. (2017) Cooking has variable effects on the fermentability in the large intestine of the fraction of meats, grain legumes, and insects that is resistant to digestion in the small intestine in an in vitro model of the pig's gastrointestinal tract. J Agric Food Chem 65, 435-444.

10. Gilbert MS, Ijssennagger N, Kies AK, et al. (2018) Protein fermentation in the gut: implications for intestinal dysfunction in humans, pigs, and poultry. Am J Physiol Gastrointest Liver Physiol 315, G159-G170.
11. Koecher KJ, Noack JA, Timm DA, et al. (2014) Estimation and interpretation of fermentation in the gut: coupling results from a $24 \mathrm{~h}$ batch in vitro system with fecal measurements from a human intervention feeding study using fructooligosaccharides, inulin, gum acacia, and pea fiber. J Agric Food Chem 62, 1332-1337.

12. Min F-F, Hu J-L, Nie S-P, et al. (2014) In vitro fermentation of the polysaccharides from Cyclocarya paliurus leaves by human fecal inoculums. Carbohydr Polym 112, 563-568.

13. Russell WR, Gratz SW, Duncan SH, et al. (2011) High-protein, reduced-carbohydrate weight-loss diets promote metabolite profiles likely to be detrimental to colonic health. Am J Clin Nutr 93, 1062-1072.

14. Binder HJ (2010) Role of colonic short-chain fatty acid transport in diarrhea. Annu Rev Physiol 72, 297-313.

15. Yang J, Martínez I, Walter J, et al. (2013) In vitro characterization of the impact of selected dietary fibers on fecal microbiota composition and short chain fatty acid production. Anaerobe 23, 74-81.

16. Leijdekkers AGM, Aguirre M, Venema K, et al. (2014) In vitro fermentability of sugar beet pulp derived oligosaccharides using human and pig fecal inocula. J Agric Food Chem 62 , 1079-1087.

17. Jonathan MC, van den Borne JJGC, van Wiechen P, et al. (2012) In vitro fermentation of 12 dietary fibres by faecal inoculum from pigs and humans. Food Chem 133, 889-897.

18. Yang J, Keshavarzian A \& Rose DJ (2013) Impact of dietary fiber fermentation from cereal grains on metabolite production by the fecal microbiota from normal weight and obese individuals. J Med Food 16, 862-867.

19. Bindels LB, Delzenne NM, Cani PD, et al. (2015) Towards a more comprehensive concept for prebiotics. Nat Rev Gastroenterol Hepatol 12, 303-310.

20. Stone G, Chapman B \& Lovell D (2009) Development of a log-quadratic model to describe microbial inactivation, illustrated by thermal inactivation of Clostridium botulinum. Appl Environ Microbiol 75, 6998-7005.

21. Kalala G, Kambashi B, Everaert N, et al. (2018) Characterization of fructans and dietary fibre profiles in raw and steamed vegetables. Int J Food Sci Nutr 69, 682-689.

22. Williams BA, Grant LJ, Gidley MJ, et al. (2017) Gut fermentation of dietary fibres: physico-chemistry of plant cell walls and implications for health. Int J Mol Sci 18, 2203.

23. Catry E, Bindels LB, Tailleux A, et al. (2018) Targeting the gut microbiota with inulin-type fructans: preclinical demonstration of a novel approach in the management of endothelial dysfunction. Gut 67, 271-283.

24. Hiel S, Neyrinck A, Rodriguez J, et al. (2018) Inulin improves postprandial hypertriglyceridemia by modulating gene expression in the small intestine. Nutrients $\mathbf{1 0}, 532$.

25. Salazar N, Dewulf EM, Neyrinck AM, et al. (2015) Inulin-type fructans modulate intestinal Bifidobacterium species populations and decrease fecal short-chain fatty acids in obese women. Clin Nutr 34, 501-507.

26. Dewulf EM, Cani PD, Claus SP, et al. (2013) Insight into the prebiotic concept: lessons from an exploratory, double blind intervention study with inulin-type fructans in obese women. Gut 62, 1112-1121.

27. Muir JG, Shepherd SJ, Rosella O, et al. (2007) Fructan and free fructose content of common Australian vegetables and fruit. J Agric Food Chem 55, 6619-6627.

28. Biesiekierski JR, Rosella O, Rose R, et al. (2011) Quantification of fructans, galacto-oligosaccharides and other short-chain carbohydrates in processed grains and cereals. J Hum Nutr Diet 24, 154-176. 
29. van Loo J, Coussement P, de Leenheer L, et al. (1995) On the presence of inulin and oligofructose as natural ingredients in the Western diet. Crit Rev Food Sci Nutr 35, 525-552.

30. Bindelle J, Buldgen A, Boudry C, et al. (2007) Effect of inoculum and pepsin-pancreatin hydrolysis on fibre fermentation measured by the gas production technique in pigs. Anim Feed Sci Technol 132, 111-122.

31. Yang J, Maldonado-Gomez MX, Hutkins RW, et al. (2014) Production and in vitro fermentation of soluble, non-digestible, feruloylated oligo- and polysaccharides from maize and wheat brans. J Agric Food Chem 62, 159-166.

32. Tran TH, Boudry C, Everaert N, et al. (2016) Adding mucins to an in vitro batch fermentation model of the large intestine induces changes in microbial population isolated from porcine feces depending on the substrate. FEMS Microbiol Ecol 92, fiv165.

33. Poelaert C, Nollevaux G, Boudry C, et al. (2018) Reducing agent can be omitted in the incubation medium of the batch in vitro fermentation model of the pig intestines. Animal 12, 1154-1164.

34. Theodorou MK, Williams BA, Dhanoa MS, et al. (1994) A simple gas production method using a pressure transducer to determine the fermentation kinetics of ruminant feeds. Anim Feed Sci Technol 48, 185-197.

35. Groot JCJ, Cone JW, Williams BA, et al. (1996) Multiphasic analysis of gas production kinetics for in vitro fermentation of ruminant feeds. Anim Feed Sci Technol 64, 77-89.

36. Schwiertz A, Taras D, Schafer K, et al. (2010) Microbiota and SCFA in lean and overweight healthy subjects. Obesity 18, 190-195.

37. Dhingra D, Michael M, Rajput $\mathrm{H}$, et al. (2012) Dietary fibre in foods: a review. J Food Sci Technol 49, 255-266.

38. Gohil DD \& Lele SS (2014) Insoluble vegetable fiber as a potential functional ingredient: in vitro studies on hypoglycemic and hypocholesterolemic effect. Am J Food Technol 2, 48-52.

39. Hernot DC, Boileau TW, Bauer LL, et al. (2009) In vitro fermentation profiles, gas production rates, and microbiota modulation as affected by certain fructans, galactooligosaccharides, and polydextrose. J Agric Food Chem 57, 1354-1361.
40. Scott KP, Gratz SW, Sheridan PO, et al. (2013) The influence of diet on the gut microbiota. Pharmacol Res 69, 52-60.

41. Hur IY \& Reicks M (2012) Relationship between wholegrain intake, chronic disease risk indicators, and weight status among adolescents in the National Health and Nutrition Examination Survey, 1999-2004. I Acad Nutr Diet 112, 46-55.

42. Weickert MO \& Pfeiffer AFH (2018) Impact of dietary fiber consumption on insulin resistance and the prevention of type 2 diabetes. J Nutr 148, 7-12.

43. Bouhnik Y, Vahedi K, Achour L, et al. (1999) Short-chain fructo-oligosaccharide administration dose-dependently increases fecal bifidobacteria in healthy humans. $J$ Nutr $\mathbf{1 2 9}$, 113-116.

44. Majid HA, Emery PW \& Whelan K (2011) Faecal microbiota and short-chain fatty acids in patients receiving enteral nutrition with standard or fructo-oligosaccharides and fibreenriched formulas. J Hum Nutr Diet Off J Br Diet Assoc 24, 260-268.

45. Rösch C, Venema K, Gruppen H, et al. (2015) Characterisation and in vitro fermentation of resistant maltodextrins using human faecal inoculum and analysis of bacterial enzymes present. Bioact Carbohydr Dietary Fibre 6, 46-53.

46. Sawicki CM, Livingston KA, Obin M, et al. (2017) Dietary fiber and the human gut microbiota: application of evidence mapping methodology. Nutrients $\mathbf{9}, 125$.

47. Uttara SR (2014) The role of soluble and insoluble fibers during fermentation of chicory root pulp. PhD Thesis, Wageningen University

48. Sasaki D, Sasaki K, Ikuta N, et al. (2018) Low amounts of dietary fibre increase in vitro production of short-chain fatty acids without changing human colonic microbiota structure. Sci Rep 8, 435-435.

49. Duncan SH, Holtrop G, Lobley G, et al. (2004) Contribution of acetate to butyrate formation by human faecal bacteria. BrJ Nutr 91, 915-923. 